\title{
Regulation of the SpvR gene of the Salmonella typhimurium virulence plasmid during exponential-phase growth in intracellular salts medium and at stationary phase in L broth
}

\author{
Julie A. Wilson $†$ and Paul A. Gulig \\ Author for correspondence: Paul A. Gulig. Tel: +1 352392 0050. Fax: +13523923133. \\ e-mail : gulig@college.med.ufl.edu
}

Department of Molecular Genetics and Microbiology, University of Florida College of Medicine, Gainesville, FL 32610-0266, USA

\begin{abstract}
The authors previously showed that the SpvR-regulated SpvABCD operon of the Salmonella typhimurium virulence plasmid is highly induced during exponential-phase growth by salmonellae intracellularly in mammalian cells and in a medium designed to mimic the intracellular environment of mammalian cells, intracellular salts medium (ISM), as well as at stationary phase in L broth (LB). The most relevant signal(s) for spv gene expression in vivo is not known. To elucidate the means by which salmonellae regulate the spv genes in response to the environment during the disease process, expression of the SpVR gene, encoding the positive regulatory protein SpvR, was examined under these same growth conditions by using RNAse-protection analysis. spvR was expressed at a low, basal level during exponential growth in LB but was induced during exponential growth in ISM and during stationary phase in LB, the same conditions that increased expression of the SPVABCD operon. Basal expression of spvR during exponential growth in LB was independent of both SpvR and the alternative sigma factor RpoS, whereas maximal induction of SpvR was dependent on both SpvR and RpoS. In an RpoSbackground, spvR message was decreased in stationary phase, whereas spvR exhibited residual Rpos-independent induction during exponential growth in ISM. Deletion of SpvA from the virulence plasmid of S. typhimurium increased expression of spvR during stationary phase in LB, but not during exponential growth in ISM. These results suggest that expression of SpvR is controlled by different regulatory factors, depending on the growth conditions encountered by the salmonellae.
\end{abstract}

Keywords: Salmonella typhimurium, virulence, regulation, expression

\section{INTRODUCTION}

The plasmid-encoded $s p v$ virulence genes of $S$. typhimurium and other non-typhoidal serovars of Salmonella enterica have been correlated with systemic salmonellosis in humans (Fang \& Fierer, 1991; Montenegro et al., 1991; Fierer et al., 1992; Gulig et al., 1993) and are essential for systemic infection in orally inoculated mice (Gulig \& Curtiss, 1987; Gulig et al., 1993). The spv

†Present address: United States Army Medical Research Institute of Infectious Diseases, Frederick, MD 21702-5011, USA.

Abbreviations: ISM, intracellular salts medium; LB, L broth; MU, Miller units. genes increase the growth rate of the salmonellae within host cells (Gulig \& Doyle, 1993), specifically macrophages (Gulig et al., 1998). However, the exact mechanism(s) by which the $s p v$ genes increase the growth rate within host cells is not known. The $s p v$ genes consist of $s p v A B C D$, which are transcribed as an operon (Krause et al., 1992) and spvR, which encodes the positive regulatory protein for the $s p v$ genes (Caldwell \& Gulig, 1991; Fang et al., 1991; Matsui et al., 1991; Taira et al., 1991). SpvR is a member of the LysR family of positive activators and regulates the transcription of the $s p v$ genes by binding to sequences upstream of $s p v A$ and $s p v R$ (Grob \& Guiney, 1996; Grob et al., 1997). However, analysis of the DNA and 
deduced amino acid sequences of $s p v A B C D$ has not aided in elucidating their function.

We previously examined the expression of the $s p v A B C D$ operon by measuring expression of $s p \nu A$ under different growth conditions in vitro, as well as intracellularly in cell culture and in infected mice (Wilson et al., 1997). It has been widely reported that the $s p v$ genes are induced during the stationary phase of growth (Fang et al., 1991; Coynault et al., 1992; Valone et al., 1993; O'Byrne \& Dorman, 1994a, b; Wilson et al., 1997). However, we also found that $s p v A$ was significantly induced when $S$. typhimurium was replicating with a generation time of $60 \mathrm{~min}$ in intracellular salts medium (ISM) (Wilson et al., 1997), a defined medium designed to mimic the intracellular environment of mammalian cells (Headley \& Payne, 1990). Furthermore, $s p v A$ was also induced when the salmonellae were replicating with a generation time of approximately $2 \mathrm{~h}$ within cultured macrophagelike cells and epithelial cells. These results raised the question of what type of signal or growth condition is most relevant for inducing expression of the $s p v$ genes in vivo in infected animal hosts.

To gain a better understanding of the mechanism of regulation of $s p v$ gene expression, we extended the analysis of $s p v$ regulation to $s p v R$. We considered the possibilities that regulation of the $s p v A B C D$ operon was governed primarily by altering the expression of the $s p v R$ regulatory gene, or that a more complex system regulates the transcription at the $s p v A$ promoter in conjunction with regulation of $s p v R$. Most previous studies examining regulation of $s p v R$ employed $l a c Z$ fusions to $s p v R$ on multicopy plasmids and overexpression of cloned $s p \nu R$ from strong promoters on multicopy plasmids. By using RNAse-protection analysis of native $s p v R$ on the virulence plasmid, we found that alterations in levels of $s p v R$ mRNA were considerably lower than those previously reported using lacZ fusions. Relevant issues involved with these studies were whether expression of $s p v R$ is qualitatively similar to that of $s p v A$, and whether $s p v R$ is similarly regulated in response to the dual signals of ISM and stationaryphase growth conditions.

We report here that, similar to $s p v A$ (Wilson et al., 1997), spvR is induced in both exponential growth in ISM and at the stationary phase of growth in L broth (LB). Like $s p v A$, stationary-phase induction of $s p v R$ expression is dependent on RpoS and SpvR, as was previously reported (Abe et al., 1994; Heiskanen et al., 1994; Kowarz et al., 1994; O'Byrne \& Dorman, 1994b; Chen et al., 1995). However, ISM induction of $s p v R$, although at a lower level, still occurs in an $\mathrm{RpoS}^{-}$ background, whereas stationary-phase expression of $s p v R$ decreases in an $\mathrm{RpoS}^{-}$background. Furthermore, SpvA represses $s p v R$, but only in relation to stationaryphase induction. Together, these data suggest that most of the regulation of the $s p v A B C D$ operon can be accounted for at the level of expression of $s p v R$ and that the ISM and stationary-phase inductions of the $s p v$ genes exhibit genetically separable components or functions.
These results were previously reported at the 94th and 95th general meetings of the American Society for Microbiology (Rogers \& Gulig, 1994; Rogers et al., 1995).

\section{METHODS}

Bacterial strains and growth conditions. The S. typhimurium strains used in this study are listed in Table 1. Wild-type, virulence-plasmid-containing $S$. typhimurium SR-11 strains $\chi 3181$ and $\chi 3306$ (gyrA1816) and isogenic virulence-plasmidcured $\chi 3337$ (gyrA1816) have been described by Gulig \& Curtiss (1987). The deletions of $s p v R, s p v A$ and $s p v B$ are represented in Fig. 1(a). All $s p v$ mutations were recombined into the virulence plasmid of $\chi 3306$ using the allelic-exchange suicide vector pCVD442 (Donnenberg \& Kaper, 1991; Wilson et al., 1997).

Unless indicated otherwise, bacteria were grown at $37^{\circ} \mathrm{C}$ with aeration in LB (Lennox, 1955) or ISM (Headley \& Payne, 1990). L agar medium was made by adding $1.5 \%(\mathrm{w} / \mathrm{v})$ agar (Difco) to LB. When appropriate, media were supplemented with antibiotics at the following concentrations: ampicillin, $100 \mu \mathrm{g} \mathrm{ml}^{-1}$; chloramphenicol, $30 \mathrm{\mu g} \mathrm{ml}^{-1}$; nalidixic acid, $25 \mu \mathrm{g} \mathrm{ml}^{-1}$; and tetracycline, $12.5 \mu \mathrm{g} \mathrm{ml}^{-1}$.

Plasmid constructs used in this study are described in Table 2. An internal, in-frame ScaI-DraI deletion in the $s p v R$ coding sequence, which removes the last two-thirds of the proposed helix-turn-helix DNA-binding domain of $s p v R$ (Caldwell \& Gulig, 1991), was constructed as follows, to yield strain UF082. The deletion was first constructed by ligating the 575 bp ClaI-Scal fragment and the $670 \mathrm{bp}$ DraI-SstII fragment of $s p v \mathrm{R}$ into ClaI-SstII-digested pBluescript $\mathrm{KS}(-)$, yielding pGTR344. A $1.2 \mathrm{~kb}$ Sall-SstI fragment containing the deletion and adjacent $s p v R$ sequences was then subcloned into pCVD442 (Donnenberg \& Kaper, 1991). The resulting suicide vector, pGTR345, was transformed into Escherichia coli S17$1 \lambda$ pir (Simon et al., 1983) to support plasmid replication and enable the plasmid to be mobilized into wild-type $S$. typhimurium $\chi 3306$ by filter conjugation. The conjugation mixture was plated on L agar containing ampicillin and nalidixic acid, to select for integration of the entire suicide plasmid into the salmonella virulence plasmid. The cointegrate strain, UF080, was then grown in the absence of ampicillin selection to enable the second recombinational event to occur. Salmonellae that had excised the suicide vector sequences were selected by plating the bacteria on sucrose plates as described by Donnenberg \& Kaper (1991). PCR analysis was performed to determine which colonies contained the deletion and which had reverted back to the wild-type. The LPS profile of each mutant was examined by silver staining LPS in SDSpolyacrylamide gels by the method of Hitchcock \& Brown (1983) to confirm that the mutants had retained smooth LPS.

A deletion of the entire $s p v A$ open reading frame, leaving the promoter for $s p v A B C D$ intact, was similarly constructed. The $0.8 \mathrm{~kb}$ Pst I fragment encoding $s p \nu A$ was deleted from a recombinant plasmid encoding the $s p v$ genes, and the sequences flanking the $\Delta$ PstI mutation were subcloned into pCVD442. The deletion was recombined into the virulence plasmid of $\chi 3306$, as described above, and the resulting strain was named UF104.

An internal, in-frame deletion of most of the $s p v B$ open reading frame was constructed by inverse PCR, using oligonucleotide primers PG69 (5'-CCCTCGAGCAGGAAAGGGGGAGTGATCAGCGC-3') and PG70 (5'-CCCTCGAGGGATCCCAAGACTTTGCAAGCCAG-3'), leaving amino acids 
Table 1. Bacterial strains used in this study.

\begin{tabular}{|c|c|c|}
\hline Strain & Relevant genotype & Comments/reference \\
\hline \multicolumn{3}{|c|}{ S. typhimurium } \\
\hline$\chi 3181$ & $\mathrm{pStSR} 100^{+}$ & Virulence plasmid positive; Gulig \& Curtiss (1987) \\
\hline$\chi 3306$ & gyrA1816 pStSR $100^{+}$ & Virulence plasmid positive, $\mathrm{Nal}^{\mathrm{r}}$; Gulig \& Curtiss (1987) \\
\hline$\chi 3337$ & gyrA1816 pStSR100- & $\begin{array}{l}\text { Virulence plasmid cured derivative of } \chi 3306, \mathrm{Nal}^{\mathrm{r}} \text {; Gulig } \\
\& \text { Curtiss (1987) }\end{array}$ \\
\hline SF1005 & $r p o S:: p R R 10$ & $A p^{r}$, source of RpoS insertion; Fang et al. (1992) \\
\hline UF005 & pStSR100(spvA9::Tn5) & Tn5 mutant of $\chi 3181, \mathrm{Kan}^{\mathrm{r}}$; Gulig et al. (1992) \\
\hline UF051 & gyrA1816 pStSR100(spvBA30) & $\begin{array}{l}1.3 \mathrm{~kb}, \mathrm{PCR} \text {-generated in-frame deletion within the } \\
\text { coding region of } s p v B \text {, derivative of } \chi 3306, \mathrm{Nal}^{\mathrm{r}} \text {; } \\
\text { H.Matsui, T. J. Doyle, C. M. Bacot } \& \text { P. A. Gulig } \\
\text { (unpublished) }\end{array}$ \\
\hline UF064 & pStSR100 ${ }^{+} r p o S::$ pRR10 & $\begin{array}{l}\text { RpoS- derivative of } \chi 3181 \text { made by P22 transduction } \\
\text { from SF1005; Wilson } \text { et al. (1997) }\end{array}$ \\
\hline UF080 & gyrA1816 pStSR100::pGTR345 & 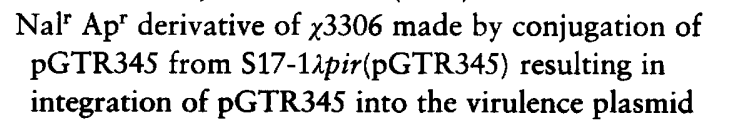 \\
\hline UF082 & gyrA1816 pStSR $100(s p v R \Delta 50)$ & $\begin{array}{l}\text { Resolution of pGTR345 from UF080, generating an in- } \\
\text { frame deletion of the } S c a \mathrm{I}-\text { DraI fragment within the } \\
\text { coding region of } s p v R, \mathrm{Nal}^{\mathrm{r}}\end{array}$ \\
\hline UF104 & gyrA1816 pStSR100(spvA 120$)$ & $\begin{array}{l}\text { Deletion of the PstI fragment encoding the entire } s p v A \\
\text { open reading frame, leaving the promoter for the } \\
s p \nu A B C D \text { operon intact. Nal }{ }^{\mathrm{r}} \text {; H. Matsui, T. J. Doyle, } \\
\text { C. M. Bacot \& P. A. Gulig (unpublished) }\end{array}$ \\
\hline \multicolumn{3}{|c|}{ Escherichia coli } \\
\hline$\chi 6060$ & 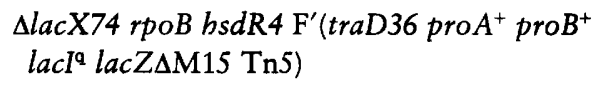 & $\begin{array}{l}\text { Recipient for transcription vector plasmids, enables } \alpha \text { - } \\
\text { complementation; Wilson et al. (1997) }\end{array}$ \\
\hline S17-1גpir & RP4-2-Tc::Mu-Km ::Tn7 $\lambda$ pir & $\begin{array}{l}\text { Host for Pir-requiring suicide plasmids, provides } \\
\text { mobilization for suicide plasmid, } \operatorname{Str}^{\mathrm{r}} \text {; Simon et al. } \\
\text { (1983) }\end{array}$ \\
\hline
\end{tabular}

1-20 and 556-592 of SpvB intact, with a leucine-glutamate linker from an engineered $\mathrm{Xhol}$ site. The deletion was subcloned into pCVD442 and was recombined into the virulence plasmid of $\chi 3306$ as described above. The resulting strain was named UF051.

S. typhimurium UF064 is strain SR-11 with the chromosomal rpoS: : pRR10 mutation of S. typhimurium SF1005 (Fang et al., 1992) constructed by P22HTint-mediated generalized transduction as described by Wilson et al. (1997).

Construction of lacZ operon fusion plasmids. All DNA manipulations were performed by standard genetic and molecular techniques (Maniatis et al., 1982; Ausubel et al., 1993). lac Z operon fusion plasmids were constructed essentially as described by Caldwell \& Gulig (1991) and are depicted in Fig. 1(b).

pGTR322 was constructed from pGTR315, which consists of sequences from the SalI site upstream of $s p v R$ to the EcoRI site downstream of $s p v R$. The lacZ,cat cartridge on a blunt-ended BamHI fragment from pSGMU32 was inserted into the HpaI site of pGTR315, yielding an $s p v R-l a c Z$ operon fusion that contained 1180 bp of upstream nontranslated $s p v R$ sequence.

Restriction analysis was used to determine the orientation of the cassette relative to the $s p v$ gene in which it was cloned. Plasmids containing lac $Z$ operon fusions were transformed or electroporated into the desired $S$. typhimurium strains for analysis of gene expression.
Construction of SpvR transcription vectors. The construction of the in vitro transcription vectors used in this study and the sizes of the cloned $s p v$ regions in each construct are summarized in Table 2. The regions of the probes containing $s p \nu R$ sequences are represented in Fig. 1(b). The spv sequences were directionally cloned in the antisense orientation into the pBluescript $\mathrm{KS}(-)$ transcription vector (Stratagene), and the ligation reactions were transformed into E. coli $\chi 6060$ (lacl $^{q}$, lacZ $\Delta M 15$ ). Plasmid constructs were verified by sequence analysis and were purified by caesium chloride centrifugation (Maniatis et al., 1982).

pGTR334 and pGTR335 were designed to measure $s p v R$ mRNA that was within the coding region. pGTR334 contains the $S c a I-D r a I$ fragment of $s p v R$ cloned into the SmaI site of pBluescript KS $(-)$. pGTR335 consists of the DraI-EcoRV fragment of $s p v R$ cloned into the SmaI site of pBluescript $\mathrm{KS}(-)$. NotI digestion of the DNA templates created the 3' ends of the antisense-RNA transcripts in the T3 run-off transcription reactions.

Measurement of $\beta$-galactosidase activity. This was performed as described by Miller (1972), except that cell debris was removed by centrifugation prior to determination of the absorbance at $420 \mathrm{~nm}$. To examine equivalent amounts of bacterial cells and ensure equal cell lysis from cxponential and stationary-phase cultures, $0.5 \mathrm{ml}$ of exponential-phase cells or $0.5 \mathrm{ml}$ of a 1:10 dilution of stationary-phase cells was used in the reactions. Enzyme activity normalized to bacterial cell 
(a)

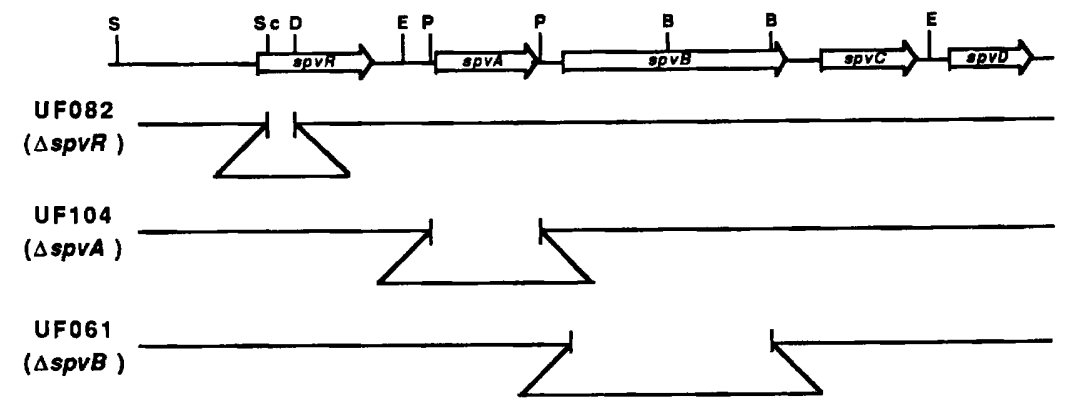

Fig. 1. (a) Location of the spv deletion mutations used to examine the effects of SpvR, SpvA and SpvB on spvR mRNA. All mutations are in the virulence plasmid of S. typhimurium $\chi 3306$. Deletions were introduced into the virulence plasmid using the allelic-exchange suicide vector, pCVD442, as described in Methods. Restriction enzyme sites: B, BamHI; D, Dral; E, EcoRI; P, Pstl; Sc, Scal; S, Sall. (b) Physical and genetic maps of the probes used to detect spvR mRNA using the RNAseprotection assay and $l a c Z$ operon fusion plasmid pGTR322 used to examine spvR expression. The spvR gene of $S$. typhimurium is depicted as the arrow in the open box. The solid bars depict the regions of the ${ }^{32} \mathrm{P}$ labelled antisense RNA probes R1 and R2, that are complementary to spvR mRNA. The orientation and insertion site of the lacZ,cat cassette is indicated by the solid arrow (not drawn to scale) at the Hpal site. Restriction enzyme sites: B, BstEll; C, Clal; D, Dral; E, ECoRI; Ev, EcoRV; H, Hpal; Sc, Scal; S, Sall.

number is presented as Miller units $(M U) \pm S D$. The values are reported as the mean \pm SD of triplicate wells. Each experiment was performed at least three times with similar results.

Isolation of bacterial RNA. Salmonella strains were grown overnight at $37^{\circ} \mathrm{C}$ as static cultures supplemented with the appropriate antibiotics. The overnight cultures were diluted to $1 \times 10^{6}$ c.f.u. $\mathrm{ml}^{-1}$ into fresh medium without antibiotics and shaken at $37^{\circ} \mathrm{C}$. Exponential-phase cultures were harvested when the cell density reached an $\mathrm{OD}_{600}$ of $0.3-0.4$; stationary-phase cultures were harvested $4-5 \mathrm{~h}$ after exponential growth ceased. Total bacterial RNA was isolated using the step-gradient caesium chloride density centrifugation method of Deretic et al. (1987) as modified by Wilson et al. (1997). Relative quantification of RNA was confirmed by examining rRNA bands on ethidium-bromide-stained agarose-formaldehyde gels (Ausubel et al., 1993).

Quantification of spvR mRNA using RNAse-protection analysis. RNAse-protection analysis was performed as previously described (Ausubel et al., 1993; Wilson et al., 1997) with ${ }^{32} \mathrm{P}$ labelled antisense RNA probes generated by T3 run-off transcription using an RNA transcription kit (Stratagene) and $\left[\alpha-{ }^{32} \mathrm{P}\right] \mathrm{CTP}$ [specific activity $3000 \mathrm{Ci} \mathrm{mmol}^{-1} \quad(111 \mathrm{TBq}-$ $\left.\mathrm{mmol}^{-1}\right)$; Amersham] according to the manufacturer's instructions. One hundred micrograms of either total bacterial RNA (for quantification of mRNA) or yeast tRNA (Boehringer Mannheim Biochemicals) (as a negative control) were hybridized with ${ }^{32} \mathrm{P}$-labelled antisense probe RNA. Following digestion of unhybridized probe and resolution on a $5 \%(\mathrm{w} / \mathrm{v})$ polyacrylamide, $7 \mathrm{M}$ urea sequencing gel, the amount of residual radiolabelled antisense probe RNA protected by $s p v R$ mRNA was quantified on a PhosphorImager (Molecular Dynamics) at the University of Florida Interdisciplinary Center for Biotechnology Research DNA Synthesis Facility. Preliminary results demonstrated that the RNase-protection assay yielded a linear dose-response curve with the levels of probe and mRNA used in this study (data not shown).

Infection of mice. Oral infection of BALB/c mice and enumeration of splenic bacteria were performed as described by Gulig \& Doyle (1993). Briefly, 7-11-week-old female $\mathrm{BALB} / \mathrm{c}$ mice (Charles River) were deprived of food and water for at least $4 \mathrm{~h}$ before administration of $50 \mu \mathrm{l} 10 \%(\mathrm{w} / \mathrm{v})$ sodium bicarbonate followed by $20 \mu \mathrm{l}$ exponential-phase salmonellae suspended in buffered saline containing $0.01 \%$ (w/v) gelatin. The total inoculum was approximately $10^{8}$ c.f.u. per mouse. Food and water were restored $30 \mathrm{~min}$ later. Five days later, the mice were killed by carbon dioxide asphyxiation, spleens were removed and homogenized in buffered saline-gelatin, and the homogenates were plated on media containing the appropriate selective antibiotics. Data are reported as mean $\pm S D$ of $\log _{10}$ c.f.u.

\section{RESULTS AND DISCUSSION}

\section{spvR is induced during exponential growth in ISM as well as stationary phase in LB}

We previously identified exponential growth of $S$. typhimurium in ISM, along with stationary phase in $\mathrm{LB}$, as growth conditions which strongly induce expression of spvA (Wilson et al., 1997). Since exponential growth in ISM with a generation time of $60 \mathrm{~min}$ is very different from stationary phase in rich media, it is conceivable that the mechanisms of regulation could be different under these conditions. We therefore examined the expression of the $s p v R$ positive regulatory gene from the virulence plasmid of wild-type S. typhimurium $\chi 3181$ grown under these two conditions. Equivalent amounts of RNA were analysed by RNAse-protection analysis 
Table 2. Plasmids used in this study

\begin{tabular}{|c|c|}
\hline Plasmid designation & Description/construction \\
\hline pACYC184 & Medium copy cloning vector; Chang \& Cohen (1978) \\
\hline pBluescript $\mathrm{KS}(-)$ & T7/T3 transcription vector; Stratagene \\
\hline pCVD442 & $\begin{array}{l}\text { Positive selection allelic exchange suicide vector; Donnenberg \& } \\
\text { Kaper (1991) }\end{array}$ \\
\hline pSGMU32 & $\begin{array}{l}\text { Promoterless lacZ,cat cassette in pUC19 used for construction of lacZ } \\
\text { operon fusions; Errington (1986) }\end{array}$ \\
\hline pYA2204 & $\begin{array}{l}\text { Low-copy cloning vector with pUC9 multiple cloning site; Galan et al. } \\
\text { (1988) }\end{array}$ \\
\hline pGTR079 & $\begin{array}{l}1.2 \mathrm{~kb} B s t \mathrm{EII}-E c o \mathrm{RI} \text { fragment of } s p v R \text { cloned into pYA2204 so that } \\
s p v R \text { is in the same orientation as the lacUV5 promoter; Caldwell \& } \\
\text { Gulig (1991) }\end{array}$ \\
\hline pGTR315 & $\begin{array}{l}2 \cdot 3 \mathrm{~kb} \text { SalI/EcoRI (blunt-ended) fragment of } s p v R \text { cloned into } \\
\text { Sall-EcoRV-digested pACYC184 }\end{array}$ \\
\hline pGTR316 & $\begin{array}{l}1.6 \mathrm{~kb} \text { blunt-ended ClaI-EcoRI fragment of } s p v R \text { cloned into EcoRV } \\
\text { site of pACYC184 }\end{array}$ \\
\hline pGTR322 & $\begin{array}{l}\text { spvR-lacZ operon fusion plasmid created by subcloning the lacZ } \\
\text { cartridge of pSGMU32 on a blunt-ended BamHI fragment into the } \\
\text { HpaI site of pGTR315 }\end{array}$ \\
\hline pGTR334 & $\begin{array}{l}\text { Transcription vector created by subcloning the } 240 \text { bp ScaI-DraI } \\
\text { fragment of pGTR316 into the SmaI site of pBluescript KS }(-)\end{array}$ \\
\hline pGTR335 & $\begin{array}{l}\text { Transcription vector created by subcloning the } 230 \text { bp DraI-EcoRV } \\
\text { fragment of pGTR } 316 \text { into the SmaI site of pBluescript } \mathrm{KS}(-)\end{array}$ \\
\hline pGTR344 & $\begin{array}{l}\text { Contains a } 240 \text { bp } S c a \mathrm{I}-D r a \mathrm{I} \text { in-frame deletion in } s p v R \text { generated by } \\
\text { triple ligation with the ClaI-ScaI and DraI-SstII fragments of } \\
\text { pGTR316 and ClaI-SstII-digested pBluescript } \mathrm{KS}(-)\end{array}$ \\
\hline pGTR345 & $\begin{array}{l}\text { Suicide vector plasmid used to delete the } 240 \text { bp ScaI-DraI fragment of } \\
s p v R \text { on the virulence plasmid. A } 1.2 \mathrm{~kb} \text { SalI-SstI fragment } \\
\text { containing the ScaI-DraI deletion on pGTR } 344 \text { was subcloned into } \\
\text { pCVD } 442 \text { cut with the same enzymes }\end{array}$ \\
\hline
\end{tabular}

$\mathrm{T}$

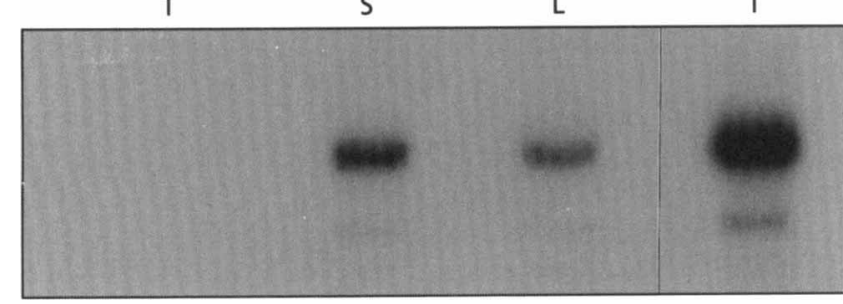

Fig. 2. The steady-state levels of spvR mRNA are increased during exponential growth in ISM and during stationary-phase growth in LB. RNA was isolated from wild-type S. typhimurium ¿3181 growing exponentially in LB (L) or ISM (I), or at stationary phase in LB (S). spvR mRNA was analysed using RNAse-protection analysis and the antisense coding region probe R1 (Fig. 1b). Yeast tRNA (T) was included as a negative control. RNA was resolved on a $5 \%$ polyacrylamide, $7 \mathrm{M}$ urea sequencing gel, visualized by autoradiography and quantified on a Phosphorlmager.

using the ${ }^{32}$ P-labelled antisense RNA probe R1 (Fig. 1b). No protected fragment corresponding to $s p v R$ mRNA was detected in negative-control samples containing yeast tRNA in the place of bacterial RNA (Fig. 2, lane $\mathrm{T})$. In addition, no protected fragments were observed upon analysis of RNA from virulence plasmid-cured $S$. typhimurium $\chi 3337$ with $s p v R$ probes (data not shown). Similar to what was observed for the spvA gene (Wilson et al., 1997), we detected a low level of $s p v R$ mRNA from salmonellae growing exponentially in LB (Fig. 2, lane $\mathrm{L}$ ); this is henceforth referred to as basal expression of $s p v R$. When the bacteria were grown to stationary phase in LB (Fig. 2, lane S), $s p v R$ was induced twofold relative to exponential phase in LB. As was previously seen for $s p v A$ mRNA (Wilson et al., 1997), the greatest amount of induction of $s p v R$ occurred when the salmonellae were growing exponentially in ISM (Fig. 2, lane I), 4.5-fold relative to exponential phase in LB. However, relative to exponential growth in ISM, the amount of $s p v R$ mRNA decreased at stationary phase in ISM (data not shown). We previously reported a similar result for $s p v A$ mRNA under the same conditions (Wilson et al., 1997). These results demonstrate that a cessation of growth does not always lead to induction of the $s p v$ genes. When we examined $s p v R$ mRNA using the second internal antisense RNA probe R2 (Fig. 1b), we obtained quantitatively similar results as with probe R1 (data not shown). Since the probes used in these assays were designed to detect internal fragments of $s p v R$ mRNA, the protected fragments which migrated 
with sizes shorter than the full length most likely represent degradation products of mRNA. When these bands were included in quantitative analysis of $\mathrm{mRNA}$ expression, similar results were obtained as for the longest, fully protected fragment.

The differential expression of $s p v A$ at stationary phase in LB and exponential-phase growth in ISM (Wilson et al., 1997) can therefore be accounted for by a qualitatively similar differential expression of the gene encoding the positive regulator, $s p v R$. However, the order of magnitude of induction was much lower for $s p \nu R$ than for $s p v A$. For example, we reported that $s p v A$ mRNA was induced 65-fold in ISM and 27-fold at stationary phase in LB (Wilson et al., 1997), whereas we report here that $s p v R$ mRNA was increased no more than 3.7-fold during stationary phase in LB and 8-fold in exponential phase in ISM. This result is consistent with $s p v R$ encoding a positive regulator, where amplification of the signal at the regulated $s p v A B C D$ operon is likely to occur. Additionally, levels of the SpvR protein could be further increased by higher rates of translation or increased protein stability as part of overall $s p v$ gene regulation.

\section{SpvR is autostimulatory during stationary phase and in ISM}

It has been reported that SpvR activates its own expression during the stationary phase of growth (Abe et al., 1994; Heiskanen et al., 1994; Kowarz et al., 1994; O'Byrne \& Dorman, 1994b; Spink et al., 1994; Chen et al., 1995; Taira et al., 1995). Those studies examined the expression of reporter genes in transcriptional or translational fusions to $s p v R$, where multicopy vectors were used to express either the reporter fusion or the cloned $s p \nu R$ gene. Furthermore, SpvR was usually expressed from a strong promoter. We initially performed similar studies to examine whether SpvR is autoregulatory during exponential growth in ISM by measuring expression of an spvR-lacZ operon fusion from a recombinant plasmid, pGTR322 (Fig. 1b), in virulenceplasmid-cured $S$. typhimurium $\chi 3337$. pGTR322 contains $1180 \mathrm{bp}$ of sequence upstream of the $s p v R$ open reading frame, which contains regulatory sequences involved in both the stationary phase and ISM inductions of $s p v R$ (Rogers \& Gulig, 1994). SpvR was provided from the low-copy recombinant plasmid pGTR079, which constitutively expresses $s p v R$ from a lacUV5 promoter (Caldwell \& Gulig, 1991). In the $\mathrm{SpvR}^{+}$background of pGTR079, expression of $s p v R-l a c Z$ from pGTR322 during exponential-phase growth in LB, stationary phase in LB and exponentialphase growth in ISM was $11 \cdot 2 \pm 0 \cdot 2 \mathrm{MU}, 1190 \pm 17 \mathrm{MU}$ and $260 \pm 0 \cdot 1 \mathrm{MU}$, respectively. Expression of $s p v R-$ lacZ in $\chi 3337$ (pGTR079, pGTR322) was therefore induced 106-fold at stationary phase in LB and 23-fold during exponential growth in ISM relative to exponential growth in LB. When the pYA2204 vector for pGTR079 was used as an SpvR ${ }^{-}$control, expression of spvR-lacZ from pGTR322 at exponential-phase growth in LB, stationary phase in LB and exponential-phase growth in ISM was $2 \cdot 4 \pm 0 \cdot 1 \mathrm{MU}, 24.8 \pm 0.6 \mathrm{MU}$ and $33.8 \pm 0.1 \mathrm{MU}$, respectively. Comparison of the $\beta$ galactosidase activity from $\chi 3337$ (pGTR079, pGTR322) and $\chi 3337$ (pYA2204, pGTR322) showed that expression of SpvR from pGTR079 increased the expression of $s p v R-l a c Z$ 5-fold during exponential growth in LB, 48-fold during stationary phase and 8-fold during exponential growth in ISM, relative to exponential-phase growth in LB.

Upon comparing the results generated using the $s p v R-$ lacZ reporter fusion with the data generated from measuring $s p v R$ mRNA from the virulence plasmid of wild-type $S$. typhimurium (Fig. 2), two inconsistencies were noted. First, the expression of $s p v R-l a c Z$ was considerably higher from $\chi 3337$ (pGTR079, pGTR322) during stationary phase in LB than in ISM, but expression of $s p v R$ mRNA from the virulence plasmid as measured by RNAse protection was higher in ISM than at stationary phase in LB. Second, the inductions of $s p \nu R$ examined using the reporter fusion (106-fold at stationary phase in LB and 23-fold during exponentialphase growth in ISM, relative to exponential phase in LB) were much higher than those observed by analysing mRNA from the virulence plasmid in wild-type salmonellae (2-fold at stationary phase in LB and 4.5-fold during exponential-phase growth in ISM). It should be noted that the direct measurement of mRNA by RNAseprotection analysis is not affected by the copy number of recombinant plasmids, stability of fusion-containing mRNAs, or stability of the $\beta$-galactosidase reporter protein.

Since we identified qualitative and quantitative differences in measuring $s p v R$ expression, depending on whether we used lacZ reporter fusions or RNAseprotection analysis for $s p v R$ mRNA, we performed RNAse-protection analysis to determine whether the positive autoregulation we detected using lac $Z$ fusions occurs when $s p v R$ is expressed from the native virulence plasmid. We constructed strain UF082 with an internal in-frame deletion of the DNA-binding region of SpvR, $s p v R \Delta 50$, which rendered the bacteria $\mathrm{SpvR}^{-}$while leaving $s p \nu R$ mRNA sequences which could be measured by using RNAse-protection analysis (Fig. 1a, b). spvR mRNA was measured from wild-type $\chi 3306$ and $s p v R \Delta 50$ UF082 growing exponentially in LB and ISM or at stationary phase in LB. Similar to the results in Fig. 2 , the steady-state levels of $s p \nu R$ mRNA from wild-type salmonellae increased when the bacteria were at stationary phase in LB (Fig. 3a, lane S) and when the bacteria were growing exponentially in ISM (Fig. $3 \mathrm{~b}$, lane I) relative to basal expression in LB (Fig. 3, lane L). The $s p v R \Delta 50$ mutation did not affect basal expression of $s p v R$ during exponential growth in LB. In contrast, in strain UF082, the steady-state levels of $s p v R$ mRNA decreased when the salmonellae were grown to stationary phase in $\mathrm{LB}$ (Fig. 3a, lane S) and $s p v R$ was no longer induced during exponential growth in ISM (Fig. 3b, lane I). These results demonstrate that SpvR is essential for both the stationary phase and ISM inductions of $s p v R$, but not basal expression of $s p v R$. 


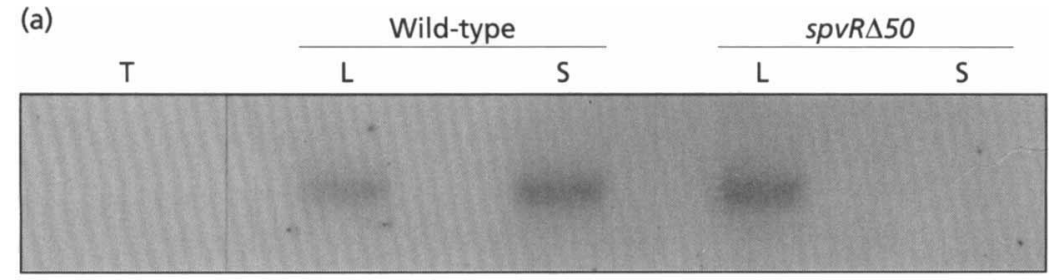

(b) Wild-type L I

(1)

spvR $\Delta 50$ L I ast $\infty$
Fig. 3. Effect of SpvR on (a) stationary phase and (b) ISM inductions of spvR. RNA isolated from S. typhimurium $\chi 3306$ (wild-type) and UF082 (spvR $\Delta 50$ ) growing exponentially in LB (L) or ISM (I), or at stationary phase in LB (S), or yeast tRNA (T) was analysed using RNAseprotection analysis with probe R2 (Fig. 1b) as described in the legend for Fig. 2.
Our results detailed above confirm those of others (Abe et al., 1994; Heiskanen et al., 1994; Kowarz et al., 1994; O'Byrne \& Dorman, 1994b; Chen et al., 1995) that SpvR is autostimulatory during stationary phase, and we extend this observation of autostimulation to exponential-phase growth in ISM. Consistent with an autoregulatory role for SpvR, DNA sequences upstream of $s p v R$ and $s p v A$ which can be bound by the SpvR protein have been identified (Matsui et al., 1993; Krause et al., 1995; Grob \& Guiney, 1996; Grob et al., 1997). By using RNAse-protection analysis and a deletion mutation in $s p v R$ on the virulence plasmid of $S$. typhimurium, we found that the low basal expression of $s p v R$ during exponential-phase growth in LB is independent of SpvR. However, functional SpvR was necessary for the induction of both $s p v R$ (Fig. 3) and $s p v A$ (Wilson et al., 1997) at stationary phase in LB and during exponential-phase growth in ISM. In contrast, Chen et al. (1995) reported that an $s p v R-l a c Z$ fusion in $S$. dublin was induced in stationary phase in the absence of expressed SpvR. This difference could be explained by the fact that Taira et al. (1995) reported a functional polymorphism in the $s p v R$ genes between $S$. typhimurium and $S$. dublin, with $S$. typhimurium having a defect in the ability of $s p v R$ to induce itself, and subsequently $s p v A$. Although we did not perform similar comparative experiments between salmonella serovars in our study, our experiments with $S$. typhimurium spvR shown above and previous expression for $s p v A$ (Wilson et al., 1997) appear to contradict Taira et al. (1995), in that SpvR induced both $s p v R$ and $s p v A$ both at stationary phase in LB and during exponential-phase growth in ISM.

\section{RpoS differentially affects the steady-state levels of spvR mRNA at stationary phase in LB and during exponential phase in ISM}

RpoS is essential for stationary-phase induction of both the $s p v A B C D$ operon (Fang et al., 1992; Heiskanen et al., 1994; Kowarz et al., 1994; Chen et al., 1995; Wilson et al., 1997) and spvR (Abe et al., 1994; Heiskanen et al., 1994; Kowarz et al., 1994; Abe \& Kawahara, 1995; Chen et al., 1995). Most studies of RpoS have concentrated on stationary-phase growth; however, dif- ferent conditions affecting levels of RpoS during exponential growth are being identified (Hengge-Aronis, 1996; Jishage et al., 1996; Muffler et al., 1997). We therefore considered the possibility that induction of $s p v R$ during exponential-phase growth in ISM might be independent of or differentially regulated by RpoS, relative to stationary phase in $\mathrm{LB}$.

To determine whether RpoS is essential for regulation of $s p v R$ during exponential-phase growth in ISM compared with expression at stationary phase in LB, we examined RNA from wild-type $S$. typhimurium $\times 3181$ and $\mathrm{RpoS}^{-}$UF064. $s p v R$ was measured using RNAseprotection analysis with the internal ScaI-DraI antisense RNA probe R1 (Fig. 1b). The rpoS mutation did not affect the basal expression of $s p \nu R$ from salmonellae growing exponentially in LB (Fig. 4, lane L). The basal expression of $s p v R$ is therefore independent of both SpvR and RpoS, suggesting that $\sigma^{70}$ can act at an $s p \nu R$ promoter independently of the SpvR protein. This result is consistent with the conclusions of others (Heiskanen et al., 1994; Kowarz et al., 1994, 1996; Chen et al., 1995). In wild-type, $\mathrm{RpoS}^{+}$salmonellae, $s p v R$ was induced 2.3fold at stationary phase (Fig. 4, lane S) relative to exponential phase in LB (Fig. 4, lane L). In contrast, the steady-state level of $s p v R$ mRNA from $\mathrm{RpoS}^{-}$salmonellae decreased by $40 \%$ in stationary phase relative to exponential-phase growth in LB, demonstrating that RpoS is essential not only for the stationary-phase induction of $s p v R$, but maintenance of even the basal level of expression at stationary phase.

When $s p v R$ mRNA was measured from wild-type $S$. typhimurium growing exponentially in ISM, $s p \nu R$ was induced 5.2-fold relative to basal expression in LB (Fig. $4 b)$. Although the level of $s p v R$ mRNA produced by RpoS $^{-}$UF064 during exponential growth in ISM was reduced compared to $\chi 3181$ under the same growth conditions, $s p v R$ was still induced $2 \cdot 6$-fold in $\mathrm{RpoS}^{-}$ salmonellae growing exponentially in ISM (Fig. 4b, lane I) relative to $\mathrm{LB}$ (Fig. 4b, lane L). This result demonstrated that both RpoS-dependent and RpoS-independent regulatory factors are involved in the induction of $s p v R$ in ISM. However, this RpoS-independent induction of $s p v R$ was not in itself sufficient to significantly increase levels of expression of $s p v A B C D$ in ISM 
(a)

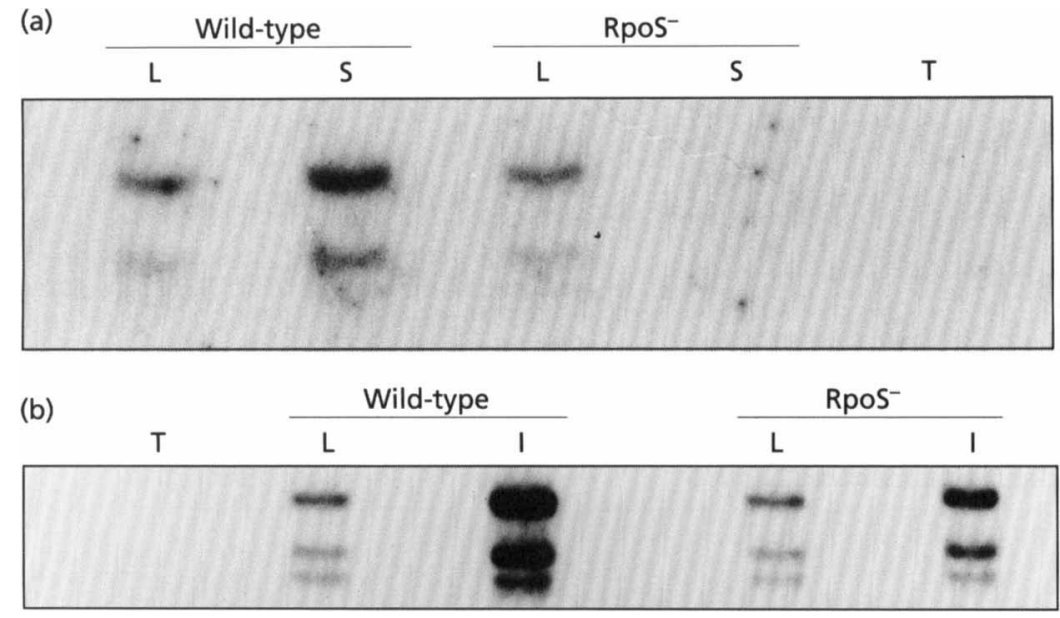

Wild-type
L

$\mathrm{S}$

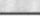

Fig. 4. Effect of Rpos on (a) stationary phase and (b) ISM inductions of spvR. RNA isolated from S. typhimurium $\chi 3306$ (wild-type) and UF064 (RpoS $)$ growing exponentially in LB (L) or ISM (I), or at stationary phase in LB (S), or yeast tRNA (T) was analysed using RNAseprotection analysis with probe R1 (Fig. 1b) as described in the legend for Fig. 2.
(Wilson et al., 1997). The divergent patterns of expression of $s p v R$ in $\mathrm{RpoS}^{-} S$. typhimurium during exponential growth in ISM and stationary phase in LB suggest that regulation of $s p v$ genes under these growth conditions possesses genetically separable components.

\section{Effect of deleting spvA or spvB on the stationary- phase and ISM inductions of spvR}

The results shown above demonstrated that both SpvR and $\mathrm{RpoS}$ are necessary for maximal induction of $s p v R$ at stationary phase in LB and during exponential-phase growth in ISM. To determine whether any of the other $s p v$ genes were involved in the regulation of $s p v R$, we examined expression of $s p v R$ mRNA from $S$. typhimurium UF005, which contains a $\operatorname{Tn} 5$ insertion in $s p v A$ with polar effects on the downstream $s p v$ genes (Gulig $e t$ al., 1992). Comparison of $s p v R$ mRNA expressed from UF005 relative to wild-type $S$. typhimurium was performed using RNAse-protection analysis on RNA isolated from salmonellae growing exponentially and at stationary phase in LB. UF005 exhibited higher levels of $s p v R$ mRNA than wild-type salmonellae during stationary phase growth in LB (data not shown), indicating that other $s p v$ genes were involved in the regulation of $s p v R$. While these studies were being performed, Abe et al. (1994) reported that overexpression of either SpvA or SpvB gave negative regulation of a cloned $S$. choleraesuis $s p v R-l a c Z$ translational fusion in E. coli. Spink et al. (1994) reported that SpvA, but not SpvB, was involved in the regulation of an $s p v R-l a c Z$ fusion in $S$. typhimurium. Both groups reported that SpvC had no effect on $s p v R$. Therefore, to determine whether either SpvA or $\mathrm{SpvB}$ contribute to the regulation of $s p v R$ expressed from the native virulence plasmid of $S$. typhimurium under our growth conditions, we compared the expression of $s p v R$ mRNA from wild-type $\chi 3306, \Delta s p v A$ UF104 and $\Delta s p v B$ UF051 growing exponentially and at stationary phase in LB, or during exponential growth in ISM. $s p \nu R$ mRNA was quantified using RNAse-protection analysis with the antisense RNA probe con- taining the internal Scal-Dral fragment of $s p v R$ (Fig. 1b, probe $\mathrm{R} 1$ ).

Wild-type S. typhimurium $\chi 3306$ growing exponentially in LB exhibited a low basal level of $s p v R$ mRNA (Fig. 5, lane L). spvR was induced 3.7-fold when the bacteria were grown to stationary phase in LB (Fig. 5a, lane S) and 8 -fold during exponential growth in ISM (Fig. 5b, lane I). The amount of $s p v R$ mRNA expressed during exponential growth in $\mathrm{LB}$, at stationary phase in $\mathrm{LB}$, or during exponential growth in ISM was not significantly different between $\Delta s p v B$ and wild-type salmonellae (Fig. 5), demonstrating that SpvB does not regulate the expression of $s p v R$ under these conditions. This result confirms those of Spink et al. (1994) and conflicts with Abe et al. (1994), who used spvR-lacZ fusions to measure $s p v R$ expression during stationary phase in $S$. typhimurium and $S$. choleraesuis, respectively.

When $s p v R$ mRNA was measured in $\Delta s p v A$ salmonellae, the steady-state level of $s p v R$ mRNA during exponential growth in LB increased slightly (1.5-fold) over basal expression in wild-type salmonellae (Fig. 5a). At stationary phase in LB, the steady-state level of $s p v R$ mRNA was 3.5-fold higher in the $\Delta s p v A$ strain relative to the wild-type parent strain (Fig. 5a, lane S), indicating that SpvA suppresses $s p v R$ expression during the stationary phase of growth in LB. In contrast, the level of $s p v R$ mRNA from the $\Delta s p v A$ strain was not significantly different from the wild-type parent during exponential growth in ISM (Fig. 5b). This result indicated that, as opposed to stationary-phase induction in LB, SpvA does not regulate the expression of $s p v R$ during exponential growth in ISM.

SpvA therefore has the potential to regulate $s p v R$ expression in a negative-feedback mechanism under specific conditions of stationary phase in rich media. Since SpvA does not contain any DNA- or RNA-binding motifs, the mechanism by which it could act to negatively regulate $s p v R$ is unknown and may require specific protein-protein interactions. Furthermore, ElGedaily et al. (1997b) recently demonstrated that SpvA 


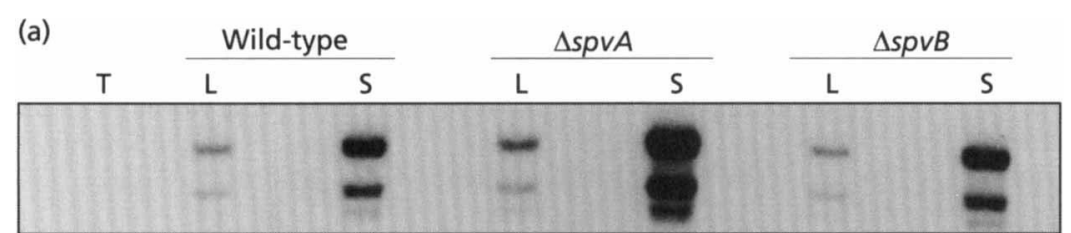

(b)

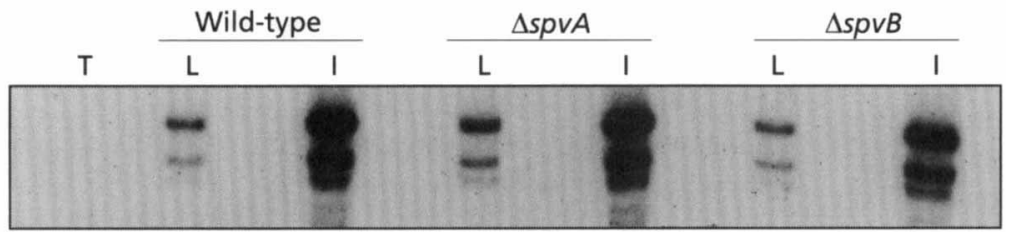

Fig. 5. Effect of $\triangle S p v A$ and $\triangle S p v B$ on (a) stationary phase and (b) ISM inductions of spvR. RNA isolated from $S$. typhimurium $\chi 3306$ (wild-type), UF104 ( $\triangle$ SpvA), or UF051 $(\Delta S p v B)$ growing exponentially in LB $(L)$ or ISM (I), or at stationary phase in LB (S), or yeast tRNA (T) was analysed using RNAseprotection analysis and probe R1 (Fig. 1b) as described in the legend for Fig. 2. is localized primarily to the outer membrane of $S$. dublin, a site not consistent with a direct regulatory function for SpvA.

We next wanted to determine whether possible negative regulation of $s p v R$ by SpvA is involved with pathogenesis. Roudier et al. (1992) addressed the role of $s p v A$ in virulence of $S$. dublin by using a translational termination mutation in $s p v A$ and reported no effect on virulence. However, they inoculated mice intraperitoneally; in S. typhimurium the spv genes are of less importance after intraperitoneal inoculation compared with oral inoculation (Gulig \& Curtiss, 1987). Therefore, we orally inoculated BALB/c mice with wild-type $S$. typhimurium $\chi 3306$ or the isogenic $\Delta s p v A$ UF104. Five days post-inoculation the $\log _{10}$ splenic c.f.u. were $4.8 \pm 0.7$ for $\chi 3306$ and $4.7 \pm 0.3$ for UF104, demonstrating that SpvA has no detectable role in virulence. In comparison, infection of mice with virulence plasmidcured $S$. typhimurium resulted in 300 -fold fewer c.f.u. per spleen, demonstrating the necessity of Spv-mediated replication to achieve the levels of infection observed for $\chi 3306$ and UF104. Therefore, although SpvA can act as a regulatory factor of $s p v R$ under stationary-phase growth conditions (but not during exponential growth in ISM), this SpvA-mediated regulation of $s p v R$ is not essential for pathogenesis in the murine model.

\section{Overall regulation of the $s p v$ genes}

Our results (Wilson et al., 1997) (Fig. 4) and those of others (Heiskanen et al., 1994; Kowarz et al., 1994, 1996; O'Byrne \& Dorman, 1994b; Chen et al., 1995) showed that RpoS is essential for maximal induction of both $s p v R$ and the $s p v A B C D$ operon. However, these data were not able to differentiate whether RpoS regulates the $s p v$ genes solely through its effects on the positive regulatory gene, $s p v R$, or whether it also acts directly at the sp $V A B C D$ promoter. The lack of induction of $s p v A$ mRNA during exponential growth in ISM in an RpoS strain (Wilson et al., 1997) even though transcription of $s p v R$ is still increased (Fig. 4) argues that RpoS is also necessary for transcription at the $s p v A$ promoter. Using $s p v-l a c Z$ reporter fusions in trans to cloned $s p v R$ and $r p o S$ genes that were under the control of exogenous promoters, two other laboratories addressed this question in S. dublin (Chen et al., 1995) and S. typhimurium (Heiskanen et al., 1994). Both studies concluded that RpoS acted at both the $s p v R$ and the $s p v A B C D$ promoters to achieve maximal expression of the $s p v$ genes during stationary-phase growth. It is also possible that RpoS indirectly influences the transcription of the $s p v$ genes by affecting either the concentration of a co-inducer molecule or another regulatory protein that is necessary for induction of the $s p v$ genes. Candidates for other regulatory proteins include bns (O'Byrne \& Dorman, 1994a), cya/crp (O'Byrne \& Dorman, 1994b) and phoP/phoQ (Heithoff et al., 1997), although their direct relation to RpoS is uncharacterized.

Since the $s p v$ genes are induced from a low, basal level under specific growth conditions and overexpression is detrimental to the salmonellae (P. A. Gulig \& J. A. Wilson, unpublished), expression of the spv genes should be tightly controlled. To account for the rapid induction of $s p v R$ under specific growth conditions, we agree with the model proposed by Chen et al. (1995). Briefly, the basal expression of the $s p v$ genes during exponential-phase growth in rich media is the result of transcription from RNA polymerase containing the sigma factor $\sigma^{70}$ and is not dependent on the plasmidencoded positive regulatory protein, SpvR. When the salmonellae attain stationary phase or are growing in the intracellular environment of an animal host, they synthesize more RpoS molecules, which compete with $\sigma^{70}$ for core RNA polymerase. The $\sigma^{\mathrm{s}}$-holoenzyme then interacts with the basal levels of SpvR in the cell to amplify expression of $s p v R$ and to induce the expression of the $s p v A B C D$ genes. Since SpvR is autostimulatory, this positive regulatory loop would enable the $s p v$ genes to be rapidly induced from a low level of expression in response to a specific signal encountered in the host. Therefore, to prevent overexpression of the $s p v$ genes, repression of $s p v R$ would be beneficial. Down-regulation of $s p v R$ could be mediated by decreasing the concentration of RpoS in the cell, by a ligand which alters the conformation of the SpvR regulatory protein, or by negative regulation by another gene product. Ligands which could affect SpvR function include short chain fatty acids (El-Gedaily et al., 1997a) and iron (Spink et al., 1994). However, the relevance of these potential regulatory molecules to induction of $s p v$ genes during exponential phase in ISM and at stationary phase 
in LB is unclear, since ISM does not contain short-chain fatty acids and neither medium is iron-depleted.

\section{Conclusions}

Our results reported here continue to demonstrate that two very different types of inductions, stationary phase in rich media and exponential-phase growth in ISM, can regulate $s p v$ gene expression through similar, yet genetically separable, mechanisms. We are interested in determining which, if any, of the these inducing and regulatory mechanisms is relevant for pathogenesis in vivo in infected animals. Since the $s p v$ genes increase the intracellular replication rate of salmonellae in vivo (Gulig \& Doyle, 1993), it is conceivable that the $s p v$ genes could be induced in vivo by a cessation of growth, which would then enable the bacteria to resume replication in the host. Alternatively, the salmonellae may induce $s p v$ expression by sensing an appropriate signal during exponential growth in an intracellular environment, thus ensuring continued intracellular growth of the salmonellae in the host before cessation of growth occurs. Identification of the relevant signal(s) involved in inducing the $s p v$ genes in vivo will aid in elucidation of the intracellular environment in which the salmonellae reside and the eventual elucidation of the mechanism by which the $s p v$ genes sustain systemic infection in the host.

\section{ACKNOWLEDGEMENTS}

This work was supported by NIH grant AI24821 to P.A.G., who is an American Heart Association Established Investigator with funds contributed in part by the American Heart Association - Florida Affiliate. J.A.W. was an American Heart Association - Florida Affiliate Graduate Fellow (92G$\mathrm{SF} / 3)$.

We thank Carleen Collins and Michael Mahan for critical review of this manuscript.

\section{REFERENCES}

Abe, A. \& Kawahara, K. (1995). Transcriptional regulation and promoter sequence of the $s p v R$ gene of virulence plasmid pKDSC50 in Salmonella choleraesuis serovar Choleraesuis. FEMS Microbiol Lett 129, 225-230.

Abe, A., Matsui, H., Danbara, H., Tanaka, K., Takahashi, H. \& Kawahara, K. (1994). Regulation of $s p v R$ gene expression of Salmonella virulence plasmid pKDSC50 in Salmonella choleraesuis serovar Choleraesuis. Mol Microbiol 12, 779-787.

Ausubel, F. M., Brent, R., Kingston, R. E., Moore, D. D., Seidman, J. G., Smith, J. A. \& Struhl, K. (1993). Current Protocols in Molecular Biology. New York: Wiley Interscience.

Caldwell, A. L. \& Gulig, P. A. (1991). The Salmonella typhimurium virulence plasmid encodes a positive regulator of a plasmidencoded virulence gene. $J$ Bacteriol 173, 7176-7185.

Chang, A. C. \& Cohen, S. N. (1978). Construction and characterization of amplifiable multicopy DNA cloning vehicles derived from the P15A cryptic miniplasmid. J Bacteriol 134, 1141-1156.

Chen, C. Y., Buchmeier, N. A., Libby, S., Fang, F. C., Krause, M. \& Guiney, D. G. (1995). Central regulatory role for the RpoS sigma factor in expression of Salmonella dublin plasmid virulence genes. J Bacteriol 177, 5303-5309.

Coynault, C., Robbe-Saule, V., Popoff, M. Y. \& Norel, F. (1992). Growth phase and SpvR regulation of transcription of Salmonella typhimurium spvABC virulence genes. Microb Pathog 13, 133143.

Deretic, V., Gill, J. F. \& Chakrabarty, A. M. (1987). Gene algD coding for GDP mannose dehydrogenase is transcriptionally activated in mucoid Pseudomonas aeruginosa. J Bacteriol 169, 351-358.

Donnenberg, M. S. \& Kaper, J. B. (1991). Construction of an eae deletion mutant of enteropathogenic Escherichia coli by using a positive-selection suicide vector. Infect Immun 59, 4310-4317.

El-Gedaily, A., Paesold, G., Chen, C.-Y., Guiney, D. G. \& Krause, $M$. (1997a). Plasmid virulence gene expression induced by shortchain fatty acids in Salmonella dublin: identification of rpoSdependent and rpoS-independent mechanisms. J Bacteriol 179, 1409-1412.

El-Gedaily, A., Paesold, G. \& Krause, M. (1997b). Expression profile and subcellular location of the plasmid-encoded virulence (Spv) proteins in wild-type Salmonella dublin. Infect Immun 35, 3406-3411.

Errington, J. (1986). A general method for fusion of the Escherichia coli lacZ gene to chromosomal genes in Bacillus subtilis. J Gen Microbiol 132, 2953-2966.

Fang, F. C. \& Fierer, J. (1991). Human infection with Salmonella dublin. Medicine 70, 198-207.

Fang, F. C., Krause, M., Roudier, C., Fierer, J. \& Guiney, D. G. (1991). Growth regulation of a Salmonella plasmid gene essential for virulence. J Bacteriol 173, 6783-6789.

Fang, F. C., Libby, S. J., Buchmeier, N. A., Loewen, P. C., Switala, J., Harwood, J. \& Guiney, D. G. (1992). The alternative sigma factor KatF (RpoS) regulates Salmonella virulence. Proc Natl Acad Sci USA 89, 11978-11982.

Fierer, J., Krause, M., Tauxe, R. \& Guiney, D. (1992). Salmonella typhimurium bacteremia: association with the virulence plasmid. J Infect Dis 166, 639-642.

Galan, J. E., Timoney, J. F. \& Curtiss, R., III (1988). Expression and localization of the Streptococcus equi $M$ protein in Escherichia coli and Salmonella typhimurium. In Proceedings of the Fifth International Conference on Equine Infectious Diseases, pp. 34-40. Edited by D. G. Powell. Lexington: University Press of Kentucky.

Grob, P. \& Guiney, D. G. (1996). In vitro binding of the Salmonella dublin virulence plasmid regulatory protein $S p v R$ to the promoter regions of $s p v A$ and $s p v R$. J Bacteriol 178, 1813-1820.

Grob, P., Kahn, D. \& Guiney, D. G. (1997). Mutational characterization of promoter regions recognized by the Salmonella dublin virulence plasmid regulatory protein SpvR. J Bacteriol 179, 5398-5406.

Gulig, P. A. \& Curtiss, R., III (1987). Plasmid-associated virulence of Salmonella typhimurium. Infect Immun 55, 2891-2901.

Gulig, P. A. \& Doyle, T. J. (1993). The Salmonella typhimurium virulence plasmid increases the growth rate of salmonellae in mice. Infect Immun 61, 504-511.

Gulig, P. A., Caldwell, A. L. \& Chiodo, V. A. (1992). Identification, genetic analysis and DNA sequence of a $7 \cdot 8$-kilobase virulence region of the Salmonella typhimurium virulence plasmid. Mol Microbiol 6, 1395-1411.

Gulig, P. A., Danbara, H., Guiney, D. G., Lax, A. J., Norel, F. \& Rhen, M. (1993). Molecular analysis of virulence genes of the Salmonella virulence plasmids. Mol Microbiol 7, 825-830. 
Gulig, P. A., Doyle, T. J., Hughes, J. A. \& Matsui, H. (1998). Analysis of host cells associated with Spv-mediated increased intracellular growth rate of Salmonella typhimurium in mice. Infect Immun 66, 2471-2485.

Headley, V. L. \& Payne, S. M. (1990). Differential protein expression by Shigella flexneri in intracellular and extracellular environments. Proc Natl Acad Sci USA 87, 4179-4183.

Heiskanen, P., Taira, S. \& Rhen, M. (1994). Role of rpoS in the regulation of Salmonella plasmid virulence $(s p v)$ genes. FEMS Microbiol Lett 123, 125-130.

Heithoff, D. M., Conner, C. P., Hanna, P. C., Julio, S. M., Hentschel, U. \& Mahan, M. J. (1997). Bacterial infection as assessed by in vivo gene expression. Proc Natl Acad Sci USA 94, 934-939.

Hengge-Aronis, R. (1996). Back to log phase: $\sigma^{\text {s }}$ as a global regulator in the osmotic control of gene expression in Escherichia coli. Mol Microbiol 21, 887-893.

Hitchcock, P. J. \& Brown, T. M. (1983). Morphological heterogeneity among Salmonella lipopolysaccharide chemotypes in silver-stained polyacrylamide gels. J Bacteriol 154, 269-277.

Jishage, M., Iwata, A., Ueda, S. \& Ishihama, A. (1996). Regulation of RNA polymerase sigma subunit synthesis in Escherichia coli: intracellular levels of four species of sigma subunit under various growth conditions. J Bacteriol 178, 5447-5451.

Kowarz, L., Coynault, C., Robbe Saule, V. \& Norel, F. (1994). The Salmonella typhimurium katF (rpoS) gene: cloning, nucleotide sequence and regulation of $s p v R$ and $s p v A B C D$ virulence plasmid genes. J Bacteriol 176, 6852-6860.

Kowarz, L., Robbe Saule, V. \& Norel, F. (1996). Identification of cis-acting DNA sequences involved in the transcription of the virulence regulatory gene $s p v R$ in Salmonella typhimurium. Mol Gen Genet 251, 225-235.

Krause, M., Fang, F. C. \& Guiney, D. G. (1992). Regulation of plasmid virulence gene expression in Salmonella dublin involves an unusual operon structure. J Bacteriol 174, 4482-4489.

Krause, M., Fang, F. C., El-Gedaily, A., Libby, S. \& Guiney, D. G. (1995). Mutational analysis of SpvR binding to DNA in the regulation of the Salmonella plasmid virulence operon. Plasmid $34,37-47$.

Lennox, E. S. (1955). Transduction of linked genetic characters of the host by bacteriophage P1. Virology 1, 190-206.

Maniatis, T., Fritsch, E. F. \& Sambrook, J. (1982). Molecular Cloning: a Laboratory Manual. Cold Spring Harbor, NY : Cold Spring Harbor Laboratory.

Matsui, H., Abe, A., Kawahara, K., Terakado, N. \& Danbara, H. (1991). Positive regulator for the expression of Mba protein of the virulence plasmid, pKDSC50, of Salmonella choleraesuis. Microb Pathog 10, 459-464.

Matsui, H., Abe, A., Suzuki, S., Kijima, M., Tamura, Y., Nakamura, M., Kawahara, K. \& Danbara, H. (1993). Molecular mechanism of the regulation of expression of plasmid-encoded mouse bacteremia $(m b a)$ genes in Salmonella serovar choleraesuis. Mol Gen Genet 236, 219-226.

Miller, J. H. (1972). Assay of beta-galactosidase. In Experiments in Molecular Genetics, pp. 353-355. Edited by J. H. Miller. Cold Spring Harbor, NY: Cold Spring Harbor Laboratory.
Montenegro, M. A., Morelli, G. \& Helmuth, R. (1991). Heteroduplex analysis of Salmonella virulence plasmids and their prevalence in isolates of defined sources. Microb Pathog 11, 391-397.

Muffler, A., Barth, M., Marchall, C. \& Hengge-Aronis, R. (1997). Heat shock regulation of $\sigma^{\mathrm{s}}$ turnover: a role for DnaK and relationship between stress responses mediated by $\sigma^{s}$ and $\sigma^{32}$ in Escherichia coli. J Bacteriol 179, 445-452.

O'Byrne, C. P. \& Dorman, C. J. (1994a). Transcription of the Salmonella typhimurium $s p v$ virulence locus is regulated negatively by the nucleoid-associated protein H-NS. FEMS Microbiol Lett 121, 99-105.

O'Byrne, C. P. \& Dorman, C. J. (1994b). The $s p v$ virulence operon of Salmonella typhimurium LT2 is regulated negatively by the cyclic AMP (cAMP)-cAMP receptor protein system. J Bacteriol 176, 905-912.

Rogers, J. A. \& Gulig, P. A. (1994). Expression and molecular regulation of the $s p v R$ gene of the Salmonella typhimurium virulence plasmid. In Abstracts of the 94th Annual Meeting of the American Society for Microbiology, abstract B323. Washington DC: American Society for Microbiology.

Rogers, J. A., Matsui, H. \& Gulig, P. A. (1995). $s p v A$ of the Salmonella typhimurium virulence plasmid can act as a transcriptional repressor of $s p v R$ and is not essential for virulence in orally inoculated mice. In Abstracts of the 94th Annual Meeting of the American Society for Microbiology, abstract B304. Washington DC: American Society for Microbiology.

Roudier, C., Fierer, J. \& Guiney, D. G. (1992). Characterization of translation termination mutations in the $s p v$ operon of the Salmonella virulence plasmid pSDL2. J Bacteriol 174, 6418-6423.

Simon, R., Priefer, U. \& Puhler, A. (1983). A broad host range mobilization system for in vivo genetic engineering: transposon mutagenesis in gram negative bacteria. Bio/Technology 1 , 784-791.

Spink, J. M., Pullinger, G. D., Wood, M. W. \& Lax, A. J. (1994). Regulation of $s p v R$, the positive regulatory gene of Salmonella plasmid virulence genes. FEMS Microbiol Lett 116, 113-121.

Taira, S., Riikonen, P., Saarilahti, H., Sukupolvi, S. \& Rhen, M. (1991). The $m k a C$ virulence gene of the Salmonella serovar Typhimurium $96 \mathrm{~kb}$ plasmid encodes a transcriptional activator. Mol Gen Genet 228, 381-384.

Taira, S., Heiskanen, P., Hurme, R., Heikkila, H., Riikonen, P. \& Rhen, M. (1995). Evidence for functional polymorphism of the $s p \nu R$ gene regulating virulence gene expression in Salmonella. Mol Gen Genet 246, 437-444.

Valone, S. E., Chikami, G. K. \& Miller, V. L. (1993). Stress induction of the virulence proteins (SpvA, $-B$, and $-C$ ) from native plasmid pSDL2 of Salmonella dublin. Infect Immun 61, 705-713.

Wilson, J. A., Doyle, T. J. \& Gulig, P. A. (1997). Exponential-phase expression of spvA of the Salmonella typhimurium virulence plasmid: induction in intracellular salts medium and intracellularly in mice and cultured mammalian cells. Microbiology $143,3827-3839$.

Received 16 October 1997; revised 26 February 1998; accepted 2 March 1998. 